\title{
USING BIG DATA TO MAP FORESTS, TREE BY TREE
}

TROPICAL FORESTS ARE MADE UP OF HUNDREDS OF TREE SPECIES. KNOWING WHAT FORESTS ARE MADE OF AT THE INDIVIDUAL TREE LEVEL CAN UNLOCK MANY SECRETS, NOT LEAST HOW FORESTS RESPOND TO THE EFFECTS OF CLIMATE CHANGE. PROFESSOR TIAN ZHENG, A STATISTICIAN AT COLUMBIA UNIVERSITY, USA, HAS TEAMED UP WITH PROFESSOR MARIA URIARTE, AN ECOLOGIST, TO COMBINE THEIR SKILLS WITH BIG DATA AND ECOLOGICAL KNOW-HOW TO MAP TREE SPECIES IN TROPICAL FORESTS

\section{GLOSSARY}

\section{ARTIFICIAL INTELLIGENCE}

the science of developing computer systems that can perform tasks usually reserved for humans, such as visual perception and

BIG DATA - extremely large datasets, within which computer programs may be able to recognise patterns or trends

\section{LIDAR (LIGHT DETECTION AND}

RANGING) - a remote sensing method that uses a pulsed laser to measure distances between things decision-making

MACHINE LEARNING - a field of artificial intelligence, specifically concerning the development of computer programs that can learn and adapt without human intervention

REMOTE SENSING - using satellites or aircraft to capture data about the Earth's surface

AERIAL IMAGING - a remote sensing method whereby drones, or manned aircraft, equipped with a high-resolution camera and LiDAR take images of the forest, which can then be processed and analysed

Climate change is already having a profound effect on the world, not least through the rising frequency and intensity of cyclonic storms. Scientists know that powerful storms such as hurricanes can cause a lot of damage to forests, but how forests recover from these impacts is less well understood. There are winners and losers, with some species benefiting from storms at the expense of others. This has big implications for mitigating climate change, too: forests absorb a fifth of the carbon that we emit, but storms can release stored carbon and change the dominance of different species.
Understanding how hurricanes affect forests is a task that cannot be tackled by one scientific discipline alone. In Columbia University in New York City, this recognition has led to a unique collaboration. Professor Tian Zheng works in the Department of Statistics at Columbia and is also a member of Columbia's Data Science Institute, while her colleague Professor Maria Uriarte is a tropical ecologist within the Department of Ecology, Evolution and Environmental Biology. By combining their skillsets and working with others, they have taken strides in understanding what happens to forests after storms.
SEEING THE TREES FROM THE FOREST

Mapping a forest by traditional methods is no easy task. Documenting the trees that make up a forest from the ground level involves time-consuming treks over difficult terrain and usually only results in a small proportion of a forest being sampled. Given that forests are highly complex environments, and the diversity of trees within any one forested area, there is no guarantee that the sample area even represents the rest of the forest. Nevertheless, many intrepid ecologists have undertaken extensive mapping surveys, but now they have a helping hand - in the form of modern technology.

"We are interested in using big data produced by remote sensing technology to study the spatial distribution of species," says Tian. Aerial imaging is one kind of remote sensing technology that gives researchers access to images of massive areas of forest, but there is another method that can be even more revealing. LiDAR (Light Detection and Ranging) offers something different: this remote sensing technology uses lasers, emitted by apparatus on an aeroplane, for instance, which 'bounce' when they hit something below them and are then picked up again by the apparatus. By emitting thousands upon thousands of these lasers, a three-dimensional image of the world beneath is produced as a cloud of points. This is the same technology used by self-driving cars to detect the distance between themselves and 



\section{ABOUT BIG DATA AND AI}

Tian explains more about her career and opportunities within her discipline:

HOW MUCH MULTIDISCIPLINARY COLLABORATION DOES YOUR ROLE INVOLVE?

I started my career collaborating with computational biologists and geneticists. Over the years, I have collaborated with sociologists, political scientists, psychologists, climate scientists and, now, ecologists. Like John Tukey (a renowned mathematician) once said, "The best thing about being a statistician is that you get to play in everyone's backyard." I have played in many backyards!

\section{WHAT EXCITES YOU ABOUT} BIG DATA?

I am excited to be able to unleash the insights hidden within all the data we are collecting today, and how that will lead to new solutions. Machine learning offers new ways of extracting valuable information from large amounts of data.

COULD ADVANCES IN MACHINE LEARNING LEAD TO FEWER JOBS IN THE FUTURE?

I think it is unlikely. Some repetitive tasks (e.g. labelling trees from images of a forest) might be replaced by machines, but this opens the door for new creative careers to emerge. Within the development of machine learning, numerous career opportunities have already been created because every algorithm requires humans to design and optimise them. Data are not perfect, and algorithms need continuous fine-tuning to make sure they give valid conclusions. This calls for a lot of people who are talented in statistics, computer science, optimisation and data ethics.

ARE THERE MANY OPPORTUNITIES FOR STUDYING AND WORKING WITH BIG DATA, ARTIFICIAL INTELLIGENCE AND STATISTICS? Yes, there is a great need for talent in these areas across all sectors in the USA. Finding real-world, data-driven solutions to problems often requires mathematical and statistical modelling, computational technologies and expert knowledge. In particular, statistical thinking has become ever more important to understanding the potential for bias or uncertainty. These are critical factors that need to be considered if big data is to realise its potential.

\section{TIAN'S TOP TIPS}

01 If you enjoyed or continue to enjoy playing with LEGO or reading detective stories and solving crimes, then you are already prepared for a career in data science (and science, overall). The same curiosity and problem-solving skills apply to careers in data science.

02 There are a lot of similarities between a data scientist and a detective. You are using all the available tools to piece together clues. You may not succeed at first, some experiments may fail, but the joy in finally making something work and finding an answer to a problem is one of the most rewarding aspects of being a scientist.

PATHWAY FROM SGHOOL TO STATISTICIAN

Tian recommends taking courses in mathematics, statistics and coding at school/college. Other subjects, especially the sciences, can also be useful.

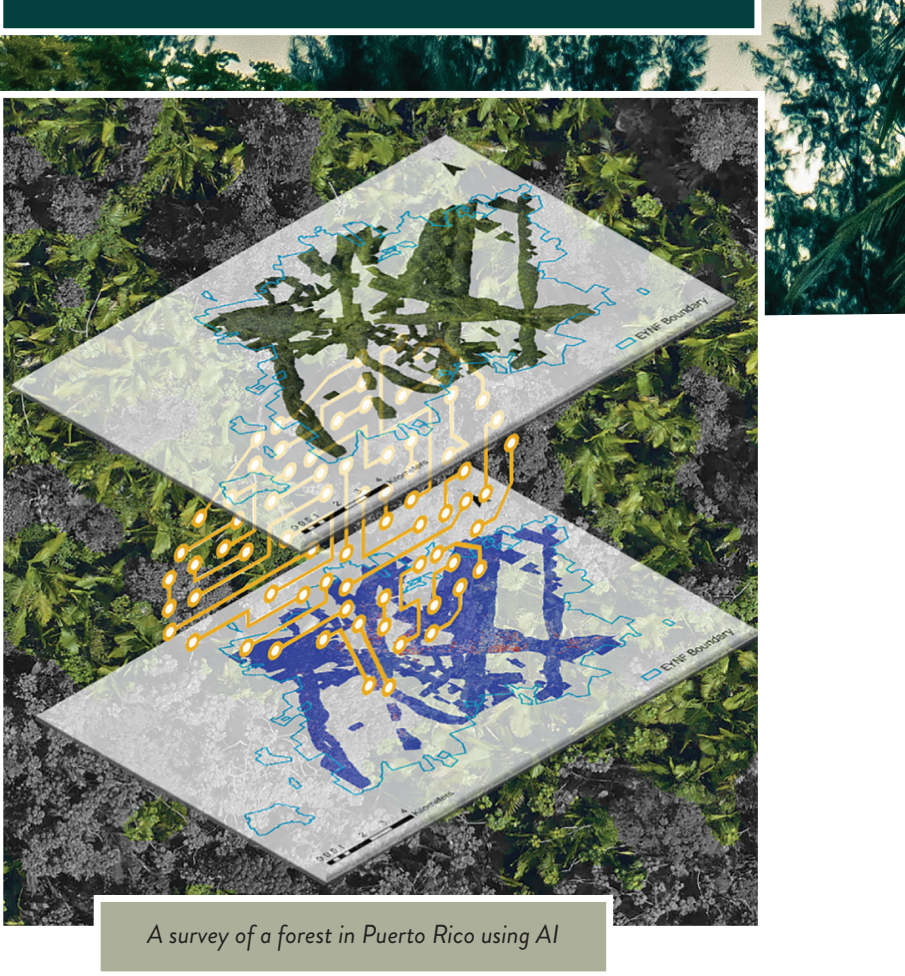




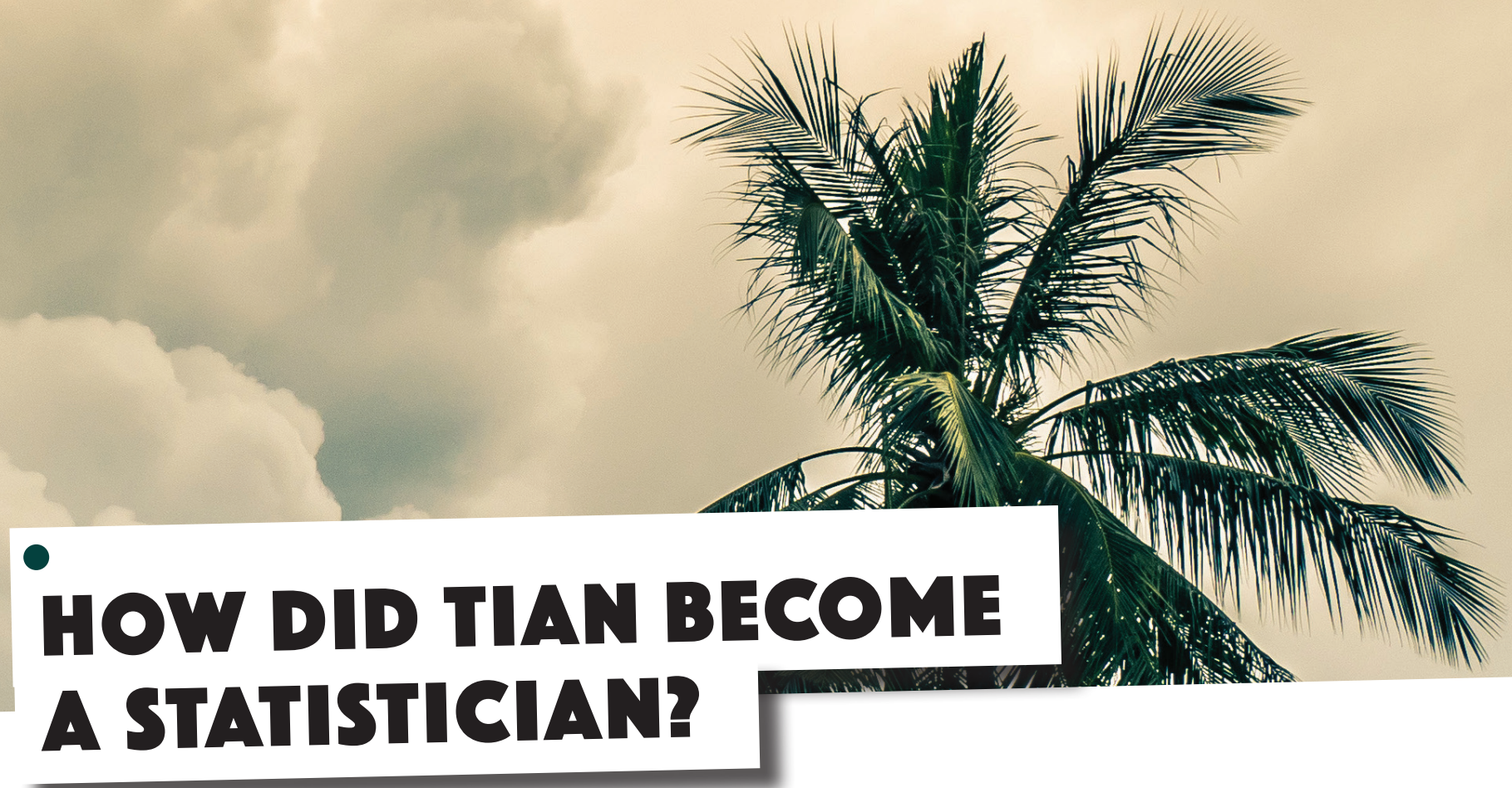

WHAT DID YOU WANT TO BE WHEN YOU WERE YOUNGER?

Originally, I wanted to be an architect, but this didn't work out. Instead, I discovered a fantastic career in mathematics!

WHAT CAREER OPTIONS WERE OPEN TO YOU AFTER COMPLETING YOUR UNDERGRADUATE DEGREE? Some of my classmates went to work for banks and research labs directly after graduation. Others, like me, continued on to graduate school.
WHAT INSPIRED YOU TO TAKE A MASTER'S AND PHD IN STATISTICS?

I have always liked solving problems.

Statistics is a field that uses data to solve problems, which was a very strong draw for me.

WHAT DO YOU LOVE MOST ABOUT YOUR WORK?

I love creating statistical models and machine learning algorithms that reveal interesting patterns in data.
YOUR TWITTER PROFILE SAYS YOU ARE A 'UNICORN TRAINER'! WHAT DOES THIS INVOLVE?

When data science first became established as a discipline, certain news articles referred to data scientists as 'unicorns'. Since I designed courses to teach students data science skills, I dubbed myself a 'unicorn trainer'!

\section{meet Chenglang tang}

Chengliang Tang is a PhD student at Columbia University who works with Tian and Maria on the tree species mapping project.

\section{WHY DID YOU CHOOSE TO STUDY MATHEMATICS AS AN} UNDERGRADUATE?

I have been interested in mathematics since high school. People say that mathematics makes up the foundation of all sciences, which I believe without a doubt.

\section{WHAT DREW YOU TO STUDY STATISTICS?}

I took courses in many different fields besides pure maths. I found statistics to be a field that revealed the beauty of mathematical theories and led to them having an impact in the real world. As we enter the era of big data, there are more and more opportunities emerging within statistics.

\section{WHAT DO YOU FIND ENJOYABLE ABOUT THE TREE SPECIES} MAPPING PROJECT?

Tian and Maria are experts in their domains, so during our weekly meetings I learn a lot from them. The project is motivated by important questions about climate change and forests, involving data collected by ecologists and meaningful outputs that help answer these questions. The significance of this project really motivates me.

\section{WHERE DO YOU SEE YOURSELF GOING NEXT?}

The world is changing rapidly, so it is difficult to predict, but I do hope to continue working in statistics. It is an exciting subject with new ideas and challenges emerging every day. I am eager to learn more, do more and contribute to our growing knowledge base.

\section{WOULD YOU ENCOURAGE OTHERS TO STUDY MATHEMATICS?}

Yes, absolutely! As well as everything I mention above, mathematics has also fundamentally shaped my way of thinking. Everyday life is full of meaningless noise, but statistics teaches you how to extract the valuable signals from within it. These changes are so gradual and imperceptible that I didn't realise they were happening until recently.

\section{WHAT ADVICE WOULD YOU GIVE TO YOUR YOUNGER SELF?}

Take more exercise! I used to undervalue physical activity, but I now realise how crucial it is for physical and mental health. Research projects are long journeys full of ups and downs. Exercise helps us keep a positive attitude and enjoy what we are doing. 